\title{
Characterization of TcSTI-1, a homologue of stress-induced protein-1, in Trypanosoma cruzi
}

\author{
Juliana C Schmidt ${ }^{2,3}$, Maurilio J Soares ${ }^{2}$, Samuel Goldenberg, ${ }^{1,2}$ \\ Daniela Parada Pavoni², Marco A Krieger ${ }^{1,2} /+$ \\ ${ }^{1}$ Instituto de Biologia Molecular do Paraná, Curitiba, PR, Brasil ²Instituto Carlos Chagas-Fiocruz, Curitiba, PR, Brasil \\ ${ }^{3}$ Universidade Comunitária da Região de Chapecó, Chapecó, SC, Brasil
}

The life cycle of the protozoan Trypanosoma cruzi exposes it to several environmental stresses in its invertebrate and vertebrate hosts. Stress conditions are involved in parasite differentiation, but little is known about the stress response proteins involved. We report here the first characterization of stress-induced protein-1 (STI-1) in T. cruzi (TcSTI-1). This co-chaperone is produced in response to stress and mediates the formation of a complex between the stress proteins HSP70 and HSP90 in other organisms. Despite the similarity of TcSTI-1 to STI-1 proteins in other organisms, its expression profile in response to various stress conditions, such as heat shock, acidic pH or nutrient starvation, is quite different. Neither polysomal $m R N A$ nor protein levels changed in exponentially growing epimastigotes cultured under any of the stress conditions studied. Increased levels of TcSTI-1 were observed in epimastigotes subjected to nutritional stress in the late growth phase. Co-immunoprecipitation assays revealed an association between TcSTI-1 and TcHSP70 in T. cruzi epimastigotes. Immunolocalization demonstrated that TcSTI-1 was distributed throughout the cytoplasm and there was some colocalization of TcSTI-1 and TcHSP70 around the nucleus. Thus, TcSTI-1 associates with TcHSP70 and TcSTI-1 expression is induced when the parasites are subjected to stress conditions during specific growth phase.

Key words: STI-1 - Hop - HSP70 - stress response - Trypanosoma cruzi

The stress-induced protein-1 (STI-1), also known as Hop (HSP70/HSP90-organising protein), is a co-chaperone that interacts with the heat-shock proteins HSP70 and HSP90 (Smith et al. 1993). This multi-chaperone complex is required for steroid receptor (SR) assembly (Chen et al. 1996, Dittmar et al. 1996, Chang et al. 1997) in which STI-1 acts as a mediator, potentially increasing the rate of SR maturation (Morishima et al. 2000). Furthermore, this chaperone complex is able to reconstitute hepadnavirus reverse transcriptase activity in vitro $\mathrm{Hu}$ et al. 2002), suggesting that a purified assembly system could be used to mediate various biological processes requiring HSP90 function (Pratt \& Toft 2003).

STI-1 acts as an adaptor protein, mediating the interaction between HSP70 and HSP90 through its tetratricopeptide repeat (TPR) domains. The N-terminal TPR domain (TPR1) specifically recognizes the C-terminus of HSP70, whereas the central TPR domain (TPR2A) binds the C-terminus of HSP90 (Chen \& Smith 1998, Scheufler et al. 2000). The C-terminal domain of STI-1 seems to be involved in the interactions with both HSPs (Flom et al. 2007, Onuoha et al. 2008). STI-1 may also modulate HSP activities (Johnson et al. 1998, Richter et al. 2003, Odunuga et al. 2004).

Financial support: CNPq, Fundação Auracária, FIOCRUZ

+ Corresponding author: mkrieger@tecpar.br

Received 13 October 2010

Accepted 21 October 2010
The STI-1 gene was first isolated and characterized in Saccharomyces cerevisiae during a genetic screen for proteins involved in the heat-shock response. The gene was named "stress-inducible" because, like other wellcharacterized HSP genes, it was induced by heat shock and by the arginine analogue canavanine. However, the nucleotide sequence of STI-1 displayed no similarity to the sequences of other HSP-encoding genes (Nicolet \& Craig 1989). Like their counterpart in yeast, the mouse and Caenorhabditis elegans STI-1 homologues are induced by heat shock (Lässle et al. 1997, Song et al. 2009). Interestingly, a soybean homologue has been shown to be induced by either heat or cold stress (Zhang et al. 2003). In addition, the upregulation of STI-1 observed in human SV-40-transformed fibroblasts or mouse macrophages exposed to bacterial lipopolysaccharide demonstrates that stress conditions unrelated to temperature may also lead to the induction of STI-1 expression (Honoré et al. 1992, Heine et al. 1999). The murine STI-1 was identified as a cytoplasmic protein (Lässle et al. 1997). However, a small fraction of STI-1 was found bound to a cellular prion protein at the cell membrane, where it promotes neuroprotection against cell death (Zanata et al. 2002). Moreover, STI-1 accumulates in the nucleus of murine fibroblasts after treatment with leptomycin B, a nuclear export inhibitor (Longshaw et al. 2004). A human homologue has also been found in the Golgi apparatus and in small vesicles within fibroblasts (Honoré et al. 1992).

A protozoan orthologue of STI- 1 has been characterized in Leishmania major and shown to be upregulated when the parasites are exposed to heat stress conditions (Webb et al. 1997). This parasite, like other trypanoso- 
matids, is exposed to various environmental conditions during its life cycle in which it alternates between invertebrate and vertebrate hosts. Experiments in vitro have shown that environmental changes, such as acidification or heat shock, trigger a change in the developmental program of the parasites, promoting their differentiation from the promastigote to the amastigote form (Zilberstein \& Shapira 1994). The differentiation of Trypanosoma brucei (the causal agent of sleeping sickness) from the vertebrate bloodstream trypomastigote form to the invertebrate procyclic form is also induced by exposure to mild acidic stress in vitro (Rolin et al. 1998). Similarly, the incubation of Trypanosoma cruzi trypomastigote forms in culture medium at $\mathrm{pH} 5.0$ for $2 \mathrm{~h}$ is sufficient to trigger their transformation into amastigote forms (Tomlinson et al. 1995). The differentiation of T. cruzi epimastigotes into metacyclic trypomastigotes is induced by nutritional stress in the insect midgut and in chemically defined conditions in vitro (Contreras et al. 1985, Kollien \& Schaub 2000).

As stress conditions trigger the transformation of trypanosomatids from one form to another throughout their life cycle, the characterization of stress response proteins should contribute to our understanding of these differentiation processes. Therefore, this work describes the first characterization of the conserved eukaryotic STI-1 orthologue in T. cruzi and investigates the interaction of STI-1 in T. cruzi (TcSTI-1) with TcHSP70. We also report the effects of various stress conditions on TcSTI-1 expression in exponentially growing epimastigotes.

\section{MATERIALS AND METHODS}

Parasite culture and stress conditions - Epimastigotes of T. cruzi clone Dm28c (Contreras et al. 1988) were maintained in the exponential growth phase by subculturing approximately $2 \times 10^{7}$ cells/mL every three days at $28^{\circ} \mathrm{C}$ in liver infusion tryptose (LIT) medium supplemented with 10\% foetal bovine serum (Camargo 1964). Epimastigotes in late growth phase were cultured for five days under the same conditions. Parasites were subjected to different stress conditions by incubation for $2 \mathrm{~h}$ either in triatomine artificial urine medium (nutritional stress), LIT medium adjusted to $\mathrm{pH} 5.0$ ( $\mathrm{pH}$ stress) or LIT medium at $37^{\circ} \mathrm{C}$ (heat stress).

Cloning and analysis of the sequence of the TcSTI-1 gene - The coding region of the T. cruzi Dm28c $S T I-1$ gene was amplified by polymerase chain reaction (PCR) using primers based on the CL Brener sequence (GeneDB systematic: Tc1047053506321.290) (TcSTI-1F 5'GGGGACAAGTTTGTACAAAAAAGCAGGCTTC ATGGACGCAACAGAACTTAAGAACAG3', TcSTI1R 5'GGGGACCACTTTGTACAAGAAAGCTGGGTC CTTTCCAAAACGAATGATTCCAGC3'), with recombination sites appended to the $5^{\prime}$ end for insertion into the pDONR221 vector (Gateway ${ }^{\mathrm{TM}}$ Platform). PCR was carried out on 100 ng of total DNA from $T$. cruzi epimastigotes. PCR reactions contained $10 \mathrm{pmol}$ of each primer, $200 \mu \mathrm{M}$ of each dNTP, 2.5 units of Pfu DNA polymerase and $P f u$ DNA polymerase buffer (Stratagene). They were cycled as follows: $94^{\circ} \mathrm{C}$ for $5 \mathrm{~min}, 10$ cycles of $94^{\circ} \mathrm{C}$ for $30 \mathrm{~s}, 62^{\circ} \mathrm{C}$ for $30 \mathrm{~s}$ and $72^{\circ} \mathrm{C}$ for $2 \mathrm{~min}$, followed by
25 cycles of $94^{\circ} \mathrm{C}$ for $30 \mathrm{~s}, 60^{\circ} \mathrm{C}$ for $30 \mathrm{~s}$ and $72^{\circ} \mathrm{C}$ for $2 \mathrm{~min}$, with a final extension step of $72^{\circ} \mathrm{C}$ for $4 \mathrm{~min}$. The amplified fragment was inserted into pDONR221 (entry vector) and transferred to pDEST17 (expression vector) according to the manufacturer's protocol (Invitrogen).

DNA sequences were analyzed using BLAST (Altschul et al. 1990) and ClustalW2 (Larkin et al. 2007) algorithms and the Lasergene sequence analysis package (DNASTAR Inc).

Production and purification of recombinant TcSTI-1 The expression construct (PCR-amplified DNA fragment inserted into pDEST17) was introduced into Escherichia coli strain BL21(DE3)pLysS (Invitrogen). Production of the $\mathrm{His}_{6}$-tagged recombinant protein was induced by adding $0.1 \mathrm{mM}$ IPTG (isopropyl- $\beta$-D-thiogalactoside) and incubating for $3 \mathrm{~h}$ at $37^{\circ} \mathrm{C}$. The recombinant protein was purified under denaturing conditions by immobilized metal affinity chromatography using a Ni-NTA agarose column (Qiagen) according to the manufacturer's protocols. Purified protein was subjected to preparative SDSPAGE and electroelution. The concentration and purity of TcSTI-1 were assessed with a Quant-IT Kit (Invitrogen) and by SDS-PAGE, respectively.

Polyclonal antiserum production and western blot analysis - Swiss mice were immunized intraperitoneally with $50 \mu \mathrm{g}$ of purified recombinant TcSTI-1 and Freund's incomplete adjuvant (Sigma) for the first inoculation and with $50 \mu \mathrm{g}$ of the recombinant protein and Alu-Gel-S suspension (SERVA) for four booster injections, administered at two-week intervals. Antiserum was obtained seven days after the last booster injection. The antiserum reacted with recombinant TcSTI-1 and specifically recognized a protein with an approximate molecular mass of $65 \mathrm{kDa}$ in $T$. cruzi whole-parasite extracts. No cross-reaction was observed with preimmune serum at dilutions of up to 1:200. The same inoculation protocol was used to obtain a polyclonal antiserum against TcGAPDH, whose molecular mass is $39 \mathrm{kDa}$. A rabbit polyclonal antiserum against TcHSP70 was kindly provided by Dr Silvane Murta, from the René Rachou Research Institute-Fiocruz.

Total protein extracts were prepared by washing parasites ( $2 \times 10^{8}$ cells) in phosphate-buffered-saline (PBS) and resuspending them in $100 \mu \mathrm{L}$ of sodium dodecyl sulfate-polyacrylamide gel electrophoresis (SDS-PAGE) sample buffer. Protein concentration was determined with a 2D-Quant Kit (Amersham). Lysate proteins were separated by SDS-PAGE through a $10 \%$ polyacrylamide gel (Laemmli 1970), transferred onto nitrocellulose membranes (Amersham) (Towbin et al. 1979) and probed with polyclonal antisera at dilutions of 1:800 (anti-TcSTI-1), 1:5000 (anti-TcHSP70) or 1:1000 (antiTcGAPDH). The resulting antigen-antibody complexes were detected using horseradish peroxidase-conjugated anti-rabbit or anti-mouse secondary antibodies (1:7500) and the enhanced chemiluminescence western blotting system (Amersham). Relative quantities of TcSTI-1 were normalized to TcGAPDH levels to control for variations in protein loading. Statistical analysis was performed by one-way ANOVA. 
Quantitative PCR (qPCR) - Parasites in exponential growth phase and subjected to different stress conditions (heat, $\mathrm{pH}$ and nutritional stresses) were used to obtain polysome-associated RNAs, as described by Goldenberg et al. (1985). Polysomal RNAs from three independent experiments were purified with the RNeasy kit (QIAGEN) and $0.5 \mu \mathrm{g}$ of RNA was converted into cDNA using oligo(dT) $)_{15}$ and ImProm-II reverse transcriptase (Promega). Using a modified version of the method described by Nardelli et al. (2007), real-time PCR assays were performed on an ABI PRISM 7500 sequence detection system (Applied Biosystems), with specific primers for STI-1 (TcSTI1qPCRF: 5'GAAGGACGCATGCGGACTCTG3', TcSTI-1qPCRR: 5'GCGCGTTTTGCCACTTCATCTC3'), H2B histone (TcH2BF: 'CGGTGGTGCGCGTCAACAAGAAGC3', TcH2BR: 5'CCAGGTCCGCCGGCAGCACGAG3') or ribosomal protein L9 (TcL9F:5'CCTTCACTGC CGTTCGTTGGTTTG3', TcL9R:5'ATGCGAGAGTGC CGTGTTGATGGT3'). The reaction mixture contained $10 \mathrm{ng}$ of cDNA, $250 \mathrm{nM}$ primer and the recommended concentration of SYBR Green master mix (Applied Biosystems). Amplifications were carried out in triplicate, with an initial denaturation step at $95^{\circ} \mathrm{C}$ for $10 \mathrm{~min}$ followed by 45 cycles of $95^{\circ} \mathrm{C}$ for $15 \mathrm{~s}, 60^{\circ} \mathrm{C}$ for $30 \mathrm{~s}$ and $72^{\circ} \mathrm{C}$ for $1 \mathrm{~min}$. Thermal dissociation and 5\% PAGE confirmed that PCR generated specific amplicons. A standard curve method, based on cycle threshold values, was used to assess expression of the TcSTI-1 gene. Triplicate 1:5 dilutions of known concentrations of cDNA were used to generate standard curves extending from $50 \mathrm{ng}-80 \mathrm{pg}$ of cDNA for each gene. Relative quantities of TcSTI-1 mRNA were normalized with respect to transcript levels of TcH2B and TcL9 control genes in various stress conditions and plotted, with unstressed epimastigotes as the reference population. Statistical analysis was performed using one-way ANOVA and Statgraphics Plus 5.0 software.

Immunofluorescence assay - Parasites were washed and resuspended at a density of $10^{7}$ cells $/ \mathrm{mL}$ in PBS. The cells were incubated for $20 \mathrm{~min}$ at room temperature (RT) to allow them to adhere to poly-L-lysine-coated slides. The samples were then fixed by incubation with $4 \%$ paraformaldehyde for $10 \mathrm{~min}$, washed in PBS and treated with $50 \mathrm{mM} \mathrm{NH} \mathrm{Cl}_{4}$ for another $10 \mathrm{~min}$. Fixed cells were permeabilized by incubation with $0.1 \%$ Triton $\mathrm{X}-100$ in PBS for 2 min and blocked by incubation overnight with $1.5 \%$ bovine serum albumin (BSA) in PBS. The cells were incubated for $1 \mathrm{~h}$ with polyclonal antisera at a dilution of 1:60 (anti-TcSTI-1) and 1:250 (anti-TcHSP70). The samples were then washed and incubated for $1 \mathrm{~h}$ with Alexa 488-conjugated goat anti-mouse antibody and Alexa 546-conjugated anti-rabbit antibody (Sigma) diluted at 1:500, as well as with DAPI $(1 \mu \mathrm{g} / \mu \mathrm{L})$. Stained slides were observed with an epifluorescence microscope (Nikon Eclipse E600) using a 100X objective.

Immunoprecipitation assay - Anti-TcSTI-1 (8 $\mu \mathrm{L})$ or anti-TcHSP70 $(2 \mu \mathrm{L})$ antiserum was incubated with about $50 \mu \mathrm{L}$ of protein G-Sepharose or protein A-Sepharose beads (Sigma), respectively, for $2 \mathrm{~h}$ at $4^{\circ} \mathrm{C}$. Mouse anti-IgG and rabbit preimmune antisera were used as controls (control beads). The beads were blocked with $1 \mathrm{mg} / \mathrm{mL}$ BSA in PBS. Antibodies were cross-linked to beads by treatment with $6.5 \mathrm{mg} / \mathrm{mL}$ dimethyl-pimedilate (Sigma) and $200 \mathrm{mM}$ triethanolamine in PBS for $30 \mathrm{~min}$ at RT, followed by washing with $200 \mathrm{mM}$ triethanolamine in PBS (the incubation and washing steps were then repeated twice). Cross-linking was stopped by adding $50 \mathrm{mM}$ ethanolamine in PBS and unbound antibodies were washed off with $200 \mathrm{mM}$ glycine (pH 2.3). Conjugated beads were washed with PBS and incubated overnight at $4^{\circ} \mathrm{C}$ in low-salt lysis buffer $(100 \mathrm{mM} \mathrm{KCl}$, $5 \mathrm{mM} \mathrm{MgCl}_{2}, 10 \mathrm{mM}$ HEPES pH 7.0, 0.5\% NP-40, $1 \mathrm{mM}$ PMSF, $1 \mu \mathrm{M}$ E-64) containing a soluble protein fraction obtained from $10^{9}$ exponentially growing epimastigotes. After three washes with 10 volumes of washing buffer $(100 \mathrm{mM} \mathrm{KCl}, 5 \mathrm{mM} \mathrm{MgCl}, 10 \mathrm{mM}$ Hepes $\mathrm{pH} 7.0,1 \%$ NP-40, 1 mM PMSF, $1 \mu \mathrm{M}$ E-64), bound proteins were eluted with one volume of $200 \mathrm{mM}$ glycine ( $\mathrm{pH}$ 2.3). Immunoprecipitated proteins were separated by SDSPAGE through a $10 \%$ polyacrylamide gel and analyzed by western blotting.

Ethics - Animal experiments were approved by the Oswaldo Cruz Foundation's Ethical Committee on Animal Experimentation (CEUA/FIOCRUZ, protocol P-0434/07).

\section{RESULTS}

The STI-1 homolog of T. cruzi - A single copy of the putative STI-1 orthologue has already been identified in the T. cruzi genome. The open reading frame of 1671 nucleotides encodes a protein containing 556 amino acid residues with a predicted molecular weight of $63.1 \mathrm{kDa}$ (El-Sayed et al. 2005).

The amino acid sequence of the protein encoded by TCSTI-1 gene displays significant similarity to the sequences of other STI-1 proteins from L. major (64\%), humans $(40 \%)$, mice $(39 \%)$, soybeans $(37 \%)$ and yeast $(37 \%)$. A comparison of the predicted STI-1 proteins is presented in Fig. 1, with the conserved amino acids indicated. Furthermore, most of the conserved residues are present in TPR motifs that mediate binding to HSP70 and HSP90 (TPR1, TPR2A and TPR2B), such as a 10amino-acid conserved sequence (NHVLYSNRSA) in TPR1 and a six-amino-acid conserved sequence (YSNRAA) in TPR2B.

Effect of different stress conditions on STI-1 expression in T. cruzi - We investigated whether STI-1 production in $T$. cruzi was induced by stress conditions, as reported for other STI-1 proteins. Levels of mRNA and protein were analyzed in epimastigotes subjected to nutritional, heat or $\mathrm{pH}$ stress for $2 \mathrm{~h}$. Relative levels of polysomal STI-1 mRNA from stressed parasites were quantified by qPCR, but no significant difference $(p>0.05)$ was found between these levels and those in unstressed parasites (Fig. 2A). A western blot analysis of steadystate levels of TcSTI-1 protein revealed no differences between stressed and unstressed epimastigotes in exponential growth phase (Fig. 2B), confirming the results obtained by qPCR. Increasing the duration of stress up to $6 \mathrm{~h}$ did not significantly alter TcSTI-1 levels (Supple- 


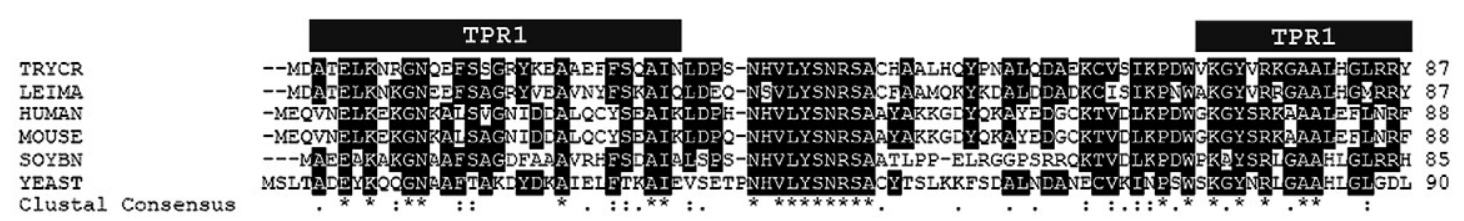

TRYCR
LEIMA
HUMAN
MOUSE
SOYBN
YEAST
Clustal Consensus
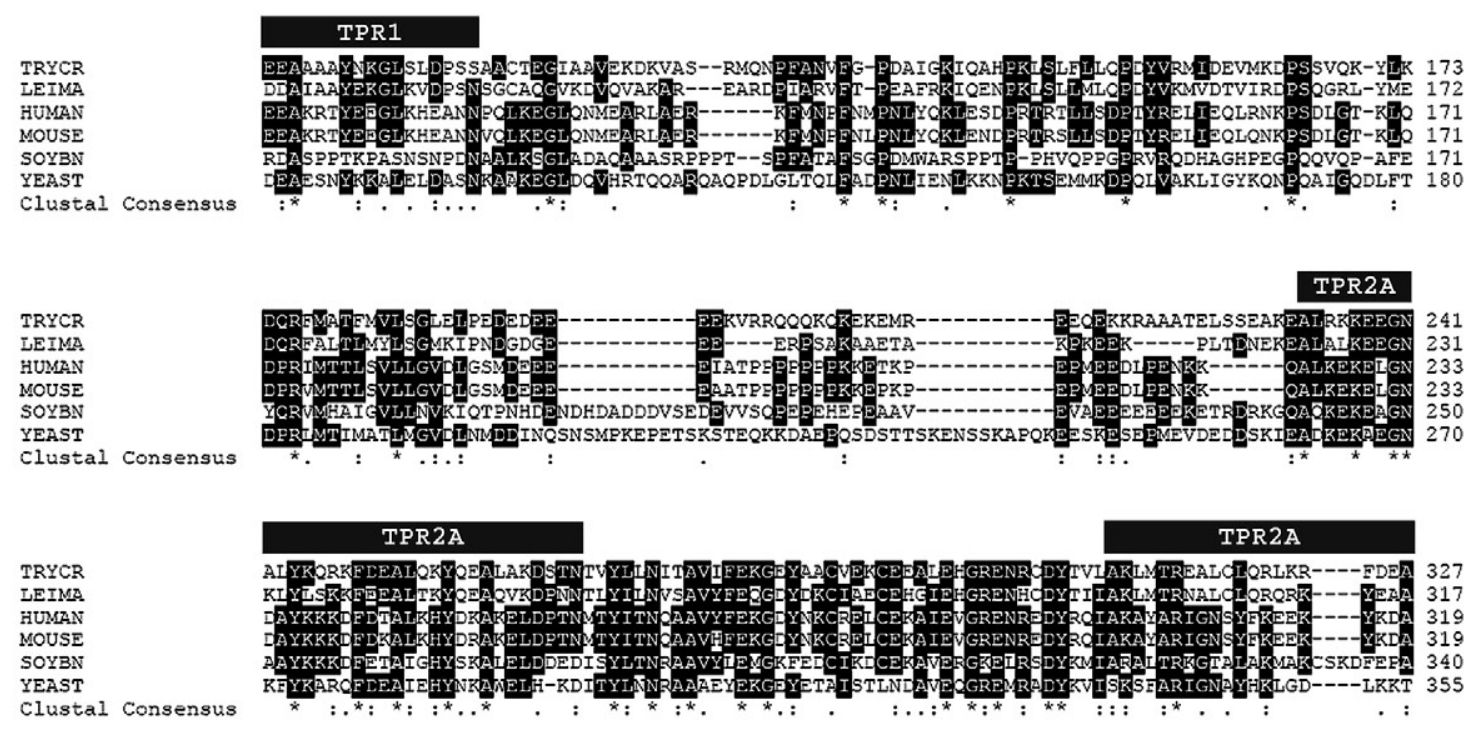

TRYCR
LEIMA
HUMAN
MOUSE
SOYBN
YEAST
Clustal Consensus
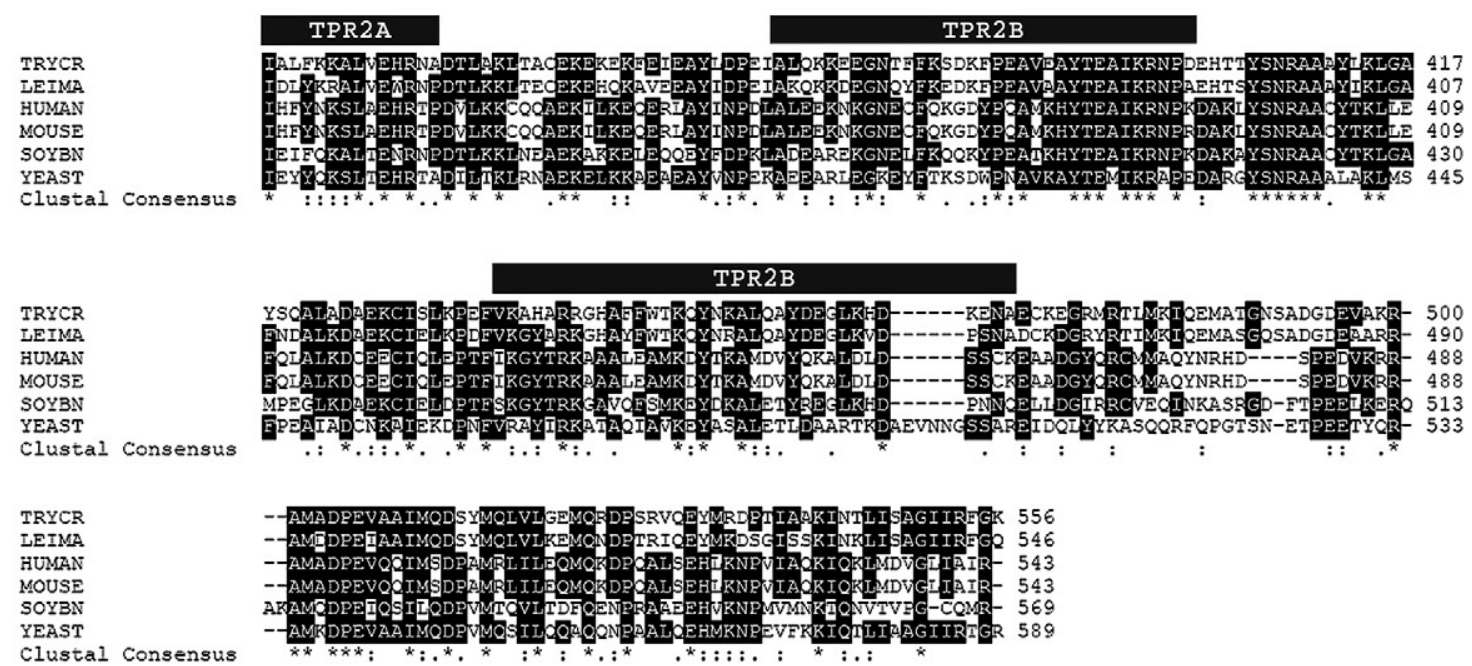

Fig. 1: comparative alignment of amino acid sequences from stress-induced protein-1 (STI-1) homologs. Translated sequences of STI-1 from Trypanosoma cruzi (TRYCR), Leishmania major (LEIMA), human, mouse, soybean (SOYBN) and yeast were analyzed with ClustalW. Tetratricopeptide repeat motifs are indicated by boxes above the residues. Residues identical in all sequences are shaded in black.

mentary data). Similarly, no changes in protein steadystate levels of TcHSP70 were observed in either assay (Fig. 2B, Supplementary data). A significant increase in TcSTI-1 levels (Fig. 3) was observed in epimastigotes in late growth phase subjected to nutritional stress (Epi 5d stressed) compared with exponentially growing epimastigotes (Epi 3d) $(p<0.05)$. These results indicate that stress-induced expression of TcSTI-1 in T. cruzi epimastigotes differs according to the growth phase during which the epimastigotes are subjected to stress.
TcSTI-1 co-immunoprecipitates and co-localizes with TcHSP70 - STI-1 is a co-chaperone known to bind heat shock proteins, such as HSP70. Co-immunoprecipitation assays were performed to determine whether this interaction also occurred in T. cruzi. Western blot analysis of the fractions eluted from beads loaded with anti-TcSTI-1 antiserum showed that TcSTI-1 and TcHSP70 co-eluted from protein extracts (Fig. 4A). Similarity, these proteins were also identified in an eluted fraction when the beads were loaded with anti-TcHSP70 serum (Fig. 4B). 
A

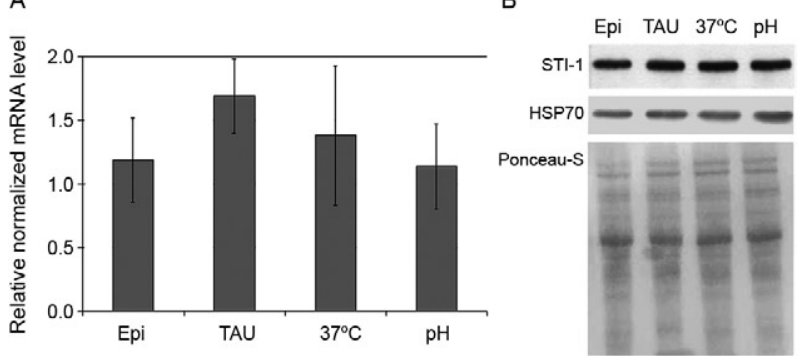

Fig. 2: stress-induced protein-1 (STI-1) in Trypanosoma cruzi polysomal mRNA and protein levels in various stress conditions. Data were obtained from unstressed T. cruzi epimastigotes in the exponential growth phase (Epi) and from epimastigotes subjected to nutritional [triatomine artificial urine (TAU)], heat $\left(37^{\circ} \mathrm{C}\right)$ or $\mathrm{pH}$ stress $(\mathrm{pH})$ for $2 \mathrm{~h}$. A: relative levels of polysome-associated STI-1 RNAs were quantified by quantitative polymerase chain reaction and normalized against mean values for the $L 9$ and $H 2 B$ control genes. Each column shows the mean values $+/$ - standard deviation for three independent experiments; B: western-blot analysis of $T$. cruzi whole-protein extracts $(20 \mu \mathrm{g})$ probed with anti-TcSTI-1 antibody $(1: 800)$ or anti-TcHSP70 (1:5000). A Ponceau-S stained membrane is shown below the western blot as a control for protein loading. This figure shows one representative result from three independent experiments.
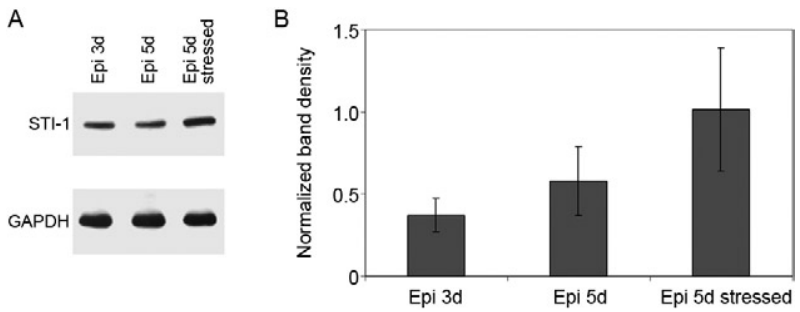

Fig. 3: stress-induced protein-1 (STI-1) in Trypanosoma cruzi (TcSTI-1) levels in epimastigotes in late growth phase. A: western-blot analysis of $T$. cruzi whole-protein extracts $(20 \mu \mathrm{g})$ obtained from unstressed $T$. cruzi epimastigotes in the exponential growth phase (Epi 3d), epimastigotes in the late growth phase (Epi 5d) and from epimastigotes in the late growth phase subjected to nutritional (Epi 5d stressed). Membranes were probed with anti-TcSTI-1 antibody (1:800) or anti-GAPDH (1:800) as a control for protein loading. This figure shows one representative result from three independent experiments; B: bands density were quantified by ImageJ program and normalized against mean values for the GAPDH control protein. Each column shows the mean values + standard deviation for three independent experiments.

Neither TcSTI-1 nor TcHSP70 was identified in fractions eluted from control beads. The co-immunoprecipitation of these two proteins suggests that STI-1 is associated with HSP70 in T. cruzi epimastigotes.

The cellular distribution of TcSTI-1 was determined by indirect immunofluorescence analysis, which showed this protein to be present in the cytoplasm of cultured (unstressed) epimastigote forms (Fig. 5B) and in epimastigotes subjected to nutritional stress (Fig. 6B). A similar pattern was observed for TcHSP70 in unstressed epimastigote forms (Fig. 5C), but a stronger signal was detected in the nucleus of stressed epimastigotes (Fig.
A

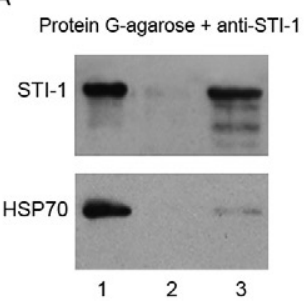

B

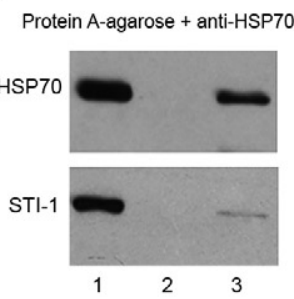

Fig. 4: co-immunoprecipitation of stress-induced protein-1 (STI-1) in Trypanosoma cruzi and TcHSP70. Agarose beads loaded with specific antisera were incubated with soluble protein extracts from exponentially growing $T$. cruzi epimastigotes. Eluted proteins were separated by SDS-PAGE in $10 \%$ polyacrylamide gels and analyzed by western blotting. Lane 1: input protein extract; 2: fraction eluted from control beads; 3: fraction eluted from beads with specific antiserum. This figure shows one representative result from two independent experiments.

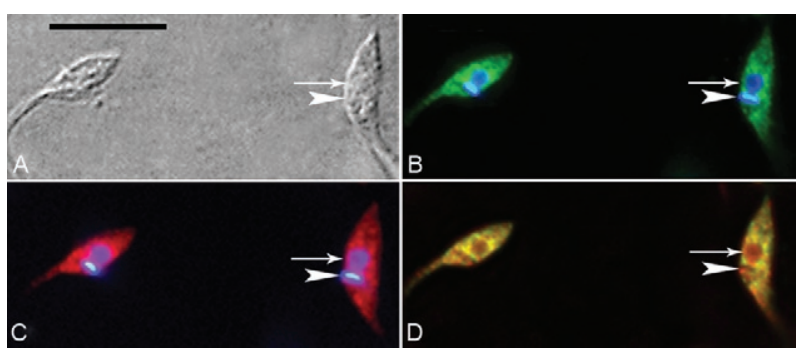

Fig. 5: immunolocalization of stress-induced protein-1 (STI-1) in Trypanosoma cruzi (TcSTI-1) protein in unstressed T. cruzi epimastigotes. Parasites were immunostained with a specific antiserum against TcSTI-1 and TcHSP70 and then incubated with AlexaFluor 488 (B, D) and with AlexaFluor $546(\mathrm{C}, \mathrm{D})$ secondary antibodies. A: cell bodies, as visualized by interferential contrast (DIC); B: merged image, showing nuclei (arrow) and kinetoplasts (arrowhead) stained in blue (DAPI) and green fluorescence for TcSTI-1; C: red fluorescence for TcHSP70. Nuclei and kinetoplasts are stained blue with DAPI; D: merged image showing green fluorescence for TcSTI-1 and red fluorescence for TcHSP70. The two proteins are colocalized throughout the cell body. Note the intense colocalization of TcST-1 and TcHSP70, visualized as yellow patches around the nuclei. Bar $=10 \mu \mathrm{m}$.

6C). Some of the signal for both these proteins was colocalized in patches around the nucleus (Fig. 5D, 6D). These results are consistent with the immunoprecipitation data, providing further support for an association between STI-1 and HSP70.

\section{DISCUSSION}

The Hop/STI-1 protein is a co-chaperone that mediates the formation of a complex between HSP70 and HSP90 (Smith et al. 1993). A recent study comparing 19 different eukaryotic organisms showed that this protein was the most widespread of the 10 co-chaperones studied (Johnson \& Brown 2009). We have demonstrated the occurrence of a Hop/STI-1 homolog in the protozoan T. cruzi (TcSTI-1), thus confirming the conservation of this protein in diverse eukaryotes. Furthermore, the STI- 

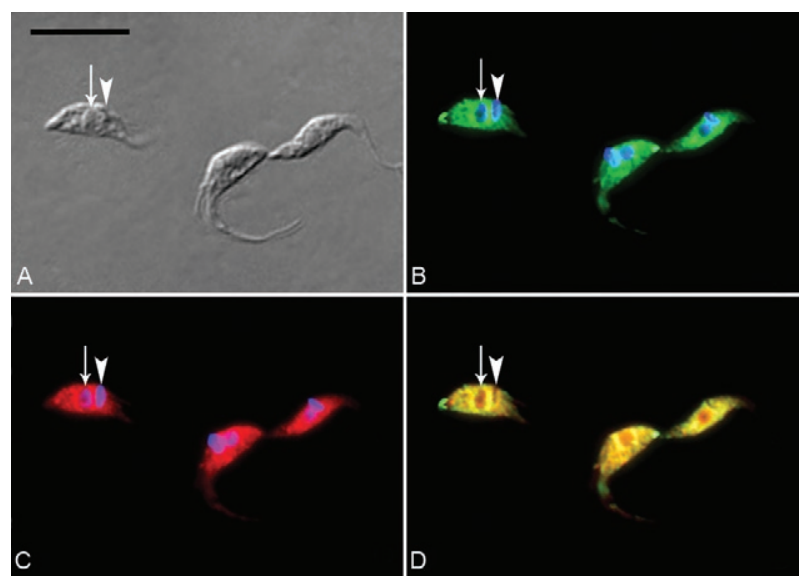

Fig. 6: immunolocalization of stress-induced protein-1 (STI-1) in Trypanosoma cruzi (TcSTI-1) protein in T. cruzi epimastigotes subjected to nutritional stress. Parasites were immunostained with a specific antiserum against TcSTI-1 and TcHSP70 and then incubated with A1exaFluor 488 (B and D) and with AlexaFluor 546 (C and D) secondary antibodies. A: cell bodies, as visualized by interferential contrast (DIC); B: merged image showing nuclei (arrow) and kinetoplasts (arrowhead) stained in blue (DAPI) and green fluorescence for TcSTI-1; C: red fluorescence for TcHSP70; nuclei and kinetoplasts are stained blue with DAPI; D: merged image showing green fluorescence for TcSTI-1 and red fluorescence for TcHSP70. Note the stronger red signal for TcHSP70 in the nuclei. Bar $=10 \mu \mathrm{m}$.

1 protein of $T$. cruzi also presents the three TPR domains characteristic of Hop/STI-1 co-chaperones in its N-terminal, central and C-terminal portions, as deduced from its amino acid sequence. These TPR domains mediate the formation of a multi-chaperone complex between HSP70 and HSP90 (Chen \& Smith 1998, Scheufler et al. 2000).

We demonstrated the association of TcSTI- 1 and TcHSP70 in T. cruzi epimastigote forms using co-immunoprecipitation and immunolocalization assays, thus suggesting that TcSTI-1 acts as an adaptor protein. It has also been reported that the incubation of parasites for $2 \mathrm{~h}$ at $37^{\circ} \mathrm{C}$ induces the translocation of TcHSP70 from the cytoplasm to the nucleus (Martin et al. 1993, Olson et al. 1994). Our data indicate that TcHSP70 is also translocated to the nucleus when parasites are subjected to nutritional stress.

Heat shock and other stress conditions have been shown to induce STI-1 expression in several organisms (Nicolet \& Craig 1989, Honoré et al. 1992, Lässle et al. 1997, Heine et al. 1999, Zhang et al. 2003, Song et al. 2009). We evaluated the stress-induced expression of the TcSTI-1 gene in exponentially growing $T$. cruzi epimastigotes subjected to nutritional, acidic or heat stress for $2 \mathrm{~h}$. We found that the incubation of exponentially growing parasites under these stress conditions resulted in no significant change in the level of the TcSTI-1 protein. A similar result was obtained in a mouse model in which steady-state STI-1 protein levels were not affected by incubation for $150 \mathrm{~min}$ at $42^{\circ} \mathrm{C}$, despite a large increase in mRNA levels (Lässle et. al. 1997). Increased levels of TcSTI-1 were observed in epimastigotes in late growth phase subjected to nutritional stress (Epi 5d stressed) compared with exponentially growing epimastigotes (Epi 3d), indicating that stress response and consequently TcSTI-1 induction in T. cruzi epimastigotes differs according to the growth phase during which the cells are subjected to stress.

Total mRNA levels have been analyzed in several organisms to evaluate the induction of STI-1 gene expression by stress conditions (Lässle et al. 1997, Webb et al. 1997, Zhang et al. 2003, Song et al. 2009). We chose to analyze only the polysome-associated mRNA fraction because gene expression in T. cruzi is predominantly regulated at the posttranscriptional level (Teixeira 1998, Clayton 2002). The mechanisms thought to be involved in regulating T. cruzi gene expression determine mRNA half-life and accessibility to the translation machinery (Goldenberg et al. 1985, da Silva et al. 2006). The recent description of P-body-like structures in T. cruzi (Holetz et al. 2007), in which mRNA may be degraded or stored in the cytoplasm, provides evidence for the existence of posttranscriptional regulatory pathways in this organism. Although gene regulation is mainly regulated by posttranscriptional mechanisms, TCSTI-1 polysomal mRNA levels were not significantly modified in stressed parasites compared with unstressed cells.

The stress response of HSP70 is not completely defined in T. cruzi. Some reports have shown that $42^{\circ} \mathrm{C}$ shock provokes mild to strong induction of HSP70 expression (de Carvalho et al. 1990, Requena et al. 1992, Olson et al. 1994). However, parasites from 48 h-old cultures do not display a classical response to heat treatment (de Carvalho et al. 1994). Our experiments, conducted using exponentially growing and stationary phase epimastigotes submitted to stress conditions, added new data to this subject. This variability of the stress responses in T. cruzi, together with the diversity of posttranscriptional gene regulation mechanisms at work in this organism, may account for the complexity in the stress response regarding to the canonical heat shock proteins expression profile. More experiments must be conducted to verify the differences in the expression of STI-1, HSP70 and other heat shock proteins subsequent to different stress challenges.

In addition to binding to HSP70 and HSP90, a small fraction of murine STI-1 binds to a cellular prion protein at the cell membrane (Zanata et al. 2002). It has been suggested that this interaction mediates neuronal survival and differentiation (Lopes et al. 2005, Arantes et al. 2009). Furthermore, STI-1 protein levels are modulated during mouse embryogenesis (Hajj et al. 2009). We are now trying to improve our understanding of the role played by TcSTI- 1 during the T. cruzi life cycle by looking for other partners of STI-1 and analyzing the pattern of STI-1 gene expression during epimastigoteto-metacyclic trypomastigote differentiation (metacyclogenesis), induced by nutritional stress in chemically defined conditions in vitro.

\section{ACKNOWLEDGEMENTS}

To Nilson Fidêncio and Andreia Dallabona, for technical support, and José Laurentino Ferreira, for statistical analysis. 


\section{REFERENCES}

Altschul SF, Gish W, Miller W, Myers EW, Lipman DJ 1990. Basic local alignment search tool. J Mol Biol 215: 403-410.

Arantes C, Nomizo R, Lopes MH, Hajj GN, Lima FR, Martins VR 2009. Prion protein and its ligand stress inducible protein 1 regulate astrocyte development. Glia 57: 1439-1449.

Camargo EP 1964. Growth and differentiation in Trypanosoma cruzi. I. Origin of metacyclic trypanosomes in liquid media. Rev Inst Med Trop Sao Paulo 6: 93-100.

Chang HC, Nathan DF, Lindquist S 1997. In vivo analysis of the Hsp90 cochaperone Sti1 (p60). Mol Cell Biol 17: 318-325.

Chen S, Prapapanich V, Rimerman RA, Honoré B, Smith DF 1996. Interactions of $\mathrm{p} 60$, a mediator of progesterone receptor assembly, with heat shock proteins hsp90 and hsp70. Mol Endocrinol 10: 682-693.

Chen S, Smith DF 1998. Hop as an adaptor in the heat shock protein 70 (Hsp70) and hsp90 chaperone machinery. J Biol Chem 273: 35194-35200.

Clayton CE 2002. Life without transcriptional control? From fly to man and back again. EMBO J 21: 1881-1888.

Contreras VT, Araujo-Jorge TC, Bonaldo MC, Thomaz N, Barbosa HS, Meirelles M de N, Goldenberg S 1988. Biological aspects of the Dm 28c clone of Trypanosoma cruzi after metacyclogenesis in chemically defined media. Mem Inst Oswaldo Cruz 83: 123-133.

Contreras VT, Salles JM, Thomas N, Morel CM, Goldenberg S 1985. In vitro differentiation of Trypanosoma cruzi under chemically defined conditions. Mol Biochem Parasitol 16: 315-327.

da Silva RA, Bartholomeu DC, Teixeira SM 2006. Control mechanisms of tubulin gene expression in Trypanosoma cruzi. Int J Parasitol 36: 87-96.

de Carvalho EF, de Castro FT, Rondinelli E, Carvalho JF 1994. Physiological aspects of Trypanosoma cruzi gene regulation during heat-shock. Biol Res 27: 225-231.

de Carvalho EF, de Castro FT, Rondinelli E, Soares CM, Carvalho JF 1990. HSP 70 gene expression in Trypanosoma cruzi is regulated at different levels. J Cell Physiol 143: 439-444.

Dittmar KD, Hutchison KA, Owens-Grillo JK, Pratt WB 1996. Reconstitution of the steroid receptor hsp 90 heterocomplex assembly system of rabbit reticulocyte lysate. J Biol Chem 271: 12833-12839.

El-Sayed NM, Myler PJ, Bartholomeu DC, Nilsson D, Aggarwal G, Tran AN, Ghedin E, Worthey EA, Delcher AL, Blandin G, Westenberger SJ, Caler E, Cerqueira GC, Branche C, Haas B, Anupama A, Arner E, Aslund L, Attipoe P, Bontempi E, Bringaud F, Burton P, Cadag E, Campbell DA, Carrington M, Crabtree J, Darban H, da Silveira JF, de Jong P, Edwards K, Englund PT, Fazelina G, Feldblyum T, Ferella M, Frasch AC, Gull K, Horn D, Hou L, Huang Y, Kindlund E, Klingbeil M, Kluge S, Koo H, Lacerda D, Levin MJ, Lorenzi H, Louie T, Machado CR, McCulloch R, McKenna A, Mizuno Y, Mottram JC, Nelson S, Ochaya S, Osoegawa K, Pai G, Parsons M, Pentony M, Pettersson U, Pop M, Ramirez JL, Rinta J, Robertson L, Salzberg SL, Sanchez DO, Seyler A, Sharma R, Shetty J, Simpson AJ, Sisk E, Tammi MT, Tarleton R, Teixeira S, Van Aken S, Vogt C, Ward PN, Wickstead B, Wortman J, White O, Fraser CM, Stuart KD, Andersson B 2005. The genome sequence of Trypanosoma cruzi, etiologic agent of Chagas disease. Science 309: 409-415.

Flom G, Behal RH, Rosen L, Cole DG, Johnson JL 2007. Definition of the minimal fragments of Stil required for dimerization, interaction with Hsp70 and Hsp90 and in vivo functions. Biochem J 404: 159-167.
Goldenberg S, Salles JM, Contreras VT, Lima Franco MP, Katzin AM, Colli W, Morel CM 1985. Characterization of messenger RNA from epimastigotes and metacyclic trypomastigotes of Trypanosoma cruzi. FEBS Lett 180: 265-270.

Hajj GN, Santos TG, Cook ZS, Martins VR 2009. Developmental expression of prion protein and its ligands stress-inducible protein 1 and vitronectin. J Comp Neurol 517: 371-384.

Heine H, Delude RL, Monks BG, Espevik T, Golenbock DT 1999. Bacterial lipopolysaccharide induces expression of the stress response genes hop and H411. J Biol Chem 274: 21049-21055.

Holetz FB, Correa A, Avila AR, Nakamura CV, Krieger MA, Goldenberg S 2007. Evidence of P-body-like structures in Trypanosoma cruzi. Biochem Biophys Res Commun 356: 1062-1067.

Honoré B, Leffers H, Madsen P, Rasmussen HH, Vandekerckhove J, Celis JE 1992. Molecular cloning and expression of a transformation-sensitive human protein containing the TPR motif and sharing identity to the stress-inducible yeast protein STI1. J Biol Chem 267: 8485-8491.

$\mathrm{Hu}$ J, Toft D, Anselmo D, Wang X 2002. In vitro reconstitution of functional hepadnavirus reverse transcriptase with cellular chaperone proteins. J Virol 76: 269-279.

Johnson BD, Schumacher RJ, Ross ED, Toft DO 1998. Hop modulates Hsp70/Hsp90 interactions in protein folding. $J$ Biol Chem 273: 3679-3686.

Johnson JL, Brown C 2009. Plasticity of the Hsp90 chaperone machine in divergent eukaryotic organisms. Cell Stress Chaperones 14: 83-94.

Kollien AH, Schaub GA 2000. The development of Trypanosoma cruzi in triatominae. Parasitol Today 16: 381-387.

Laemmli UK 1970. Cleavage of structural proteins during the assembly of the head of bacteriophage T4. Nature 227: 680-685.

Larkin MA, Blackshields G, Brown NP, Chenna R, McGettigan PA, McWilliam H, Valentin F, Wallace IM, Wilm A, Lopez R, Thompson JD, Gibson TJ, Higgins DG 2007. ClustalW and ClustalX version 2.0. Bioinformatics 23: 2947-2948.

Lässle M, Blatch GL, Kundra V, Takatori T, Zetter BR 1997. Stressinducible, murine protein mSTI1. Characterization of binding domains for heat shock proteins and in vitro phosphorylation by different kinases. J Biol Chem 272: 1876-1884.

Longshaw VM, Chapple JP, Balda MS, Cheetham ME, Blatch GL 2004. Nuclear translocation of the Hsp70/Hsp90 organizing protein mSTI1 is regulated by cell cycle kinases. J Cell Sci 117: 701-710.

Lopes MH, Hajj GN, Muras AG, Mancini GL, Castro RM, Ribeiro KC, Brentani RR, Linden R, Martins VR 2005. Interaction of cellular prion and stress-inducible protein 1 promotes neuritogenesis and neuroprotection by distinct signaling pathways. J Neurosci 25: 11330-11339.

Martin F, Requena JM, Martin J, Alonso C, López MC 1993. Cytoplasmic-nuclear translocation of the Hsp70 protein during environmental stress in Trypanosoma cruzi. Biochem Biophys Res Commun 196: 1155-1162.

Morishima Y, Kanelakis KC, Silverstein AM, Dittmar KD, Estrada L, Pratt WB 2000. The Hsp organizer protein hop enhances the rate of but is not essential for glucocorticoid receptor folding by the multiprotein Hsp90-based chaperone system. J Biol Chem 275: 6894-6900.

Nardelli SC, Avila AR, Freund A, Motta MC, Manhães L, de Jesus TC, Schenkman S, Fragoso SP, Krieger MA, Goldenberg S, Dallagiovanna B 2007. Small-subunit rRNA processome proteins are translationally regulated during differentiation of Trypanosoma cruzi. Eukaryot Cell 6: 337-345. 
Nicolet CM, Craig EA 1989. Isolation and characterization of STI1, a stress-inducible gene from Saccharomyces cerevisiae. Mol Cell Biol 9: 3638-3646.

Odunuga OO, Longshaw VM, Blatch GL 2004. Hop: more than an Hsp70/Hsp90 adaptor protein. Bioessays 26: 1058-1068.

Olson CL, Nadeau KC, Sullivan MA, Winquist AG, Donelson JE, Walsh CT, Engman DM 1994. Molecular and biochemical comparison of the 70-kDa heat shock proteins of Trypanosoma cruzi. J Biol Chem 269: 3868-3874.

Onuoha SC, Coulstock ET, Grossmann JG, Jackson SE 2008. Structural studies on the co-chaperone Hop and its complexes with Hsp90. J Mol Biol 379: 732-744.

Pratt WB, Toft DO 2003. Regulation of signaling protein function and trafficking by the hsp90/hsp70-based chaperone machinery. Exp Biol Med (Maywood) 228: 111-133.

Requena JM, Jimenez-Ruiz A, Soto M, Assiego R, Santarén JF, Lopez MC, Patarroyo ME, Alonso C 1992. Regulation of Hsp70 expression in Trypanosoma cruzi by temperature and growth phase. Mol Biochem Parasitol 53: 201-211.

Richter K, Muschler P, Hainzl O, Reinstein J, Buchner J 2003. Stil is a non-competitive inhibitor of the Hsp90 ATPase. Binding prevents the N-terminal dimerization reaction during the atpase cycle. J Biol Chem 278: 10328-10333.

Rolin S, Hancocq-Quertier J, Paturiaux-Hanocq F, Nolan DP, Pays E 1998. Mild acid stress as a differentiation trigger in Trypanosoma brucei. Mol Biochem Parasitol 93: 251-262.

Scheufler C, Brinker A, Bourenkov G, Pegoraro S, Moroder L, Bartunik H, Hartl FU, Moarefi I 2000. Structure of TPR domain-peptide complexes: critical elements in the assembly of the Hsp70Hsp90 multichaperone machine. Cell 101: 199-210.
Smith DF, Sullivan WP, Marion TN, Zaitsu K, Madden B, McCormick DJ, Toft DO 1993. Identification of a 60-kilodalton stress-related protein, p60, which interacts with Hsp90 and Hsp70. Mol Cell Biol 13: $869-876$

Song HO, Lee W, An K, Lee HS, Cho JH, Park ZY, Ahnn J 2009. C. elegans STI-1, the homolog of Sti1/Hop, is involved in aging and stress response. J Mol Biol 390: 604-617.

Teixeira SM 1998. Control of gene expression in Trypanosomatidae. Braz J Med Biol Res 31: 1503-1516.

Tomlinson S, Vandekerckhove F, Frevert U, Nussenzweig V 1995. The induction of Trypanosoma cruzi trypomastigote to amastigote transformation by low pH. Parasitology 110: 547-554.

Towbin H, Staehelin T, Gordon J 1979. Electrophoretic transfer of proteins from polyacrylamide gels to nitrocellulose sheets: procedure and some applications. Proc Natl Acad Sci USA 76: 4350-4354.

Webb JR, Campos-Neto A, Skeiky YA, Reed SG 1997. Molecular characterization of the heat-inducible LmSTI1 protein of Leishmania major. Mol Biochem Parasitol 89: 179-193.

Zanata SM, Lopes MH, Mercadante AF, Hajj GN, Chiarini LB, Nomizo R, Freitas AR, Cabral AL, Lee KS, Juliano MA, de Oliveira E, Jachieri SG, Burlingame A, Huang L, Linden R, Brentani RR, Martins VR 2002. Stress-inducible protein 1 is a cell surface ligand for cellular prion that triggers neuroprotection. EMBO J 21: 3307-3316.

Zhang Z, Quick MK, Kanelakis KC, Gijzen M, Krishna P 2003. Characterization of a plant homolog of hop, a cochaperone of hsp90. Plant Physiol 131: 525-535.

Zilberstein D, Shapira M 1994. The role of $\mathrm{pH}$ and temperature in the development of Leishmania parasites. Annu Rev Microbiol 48: 449-470. 

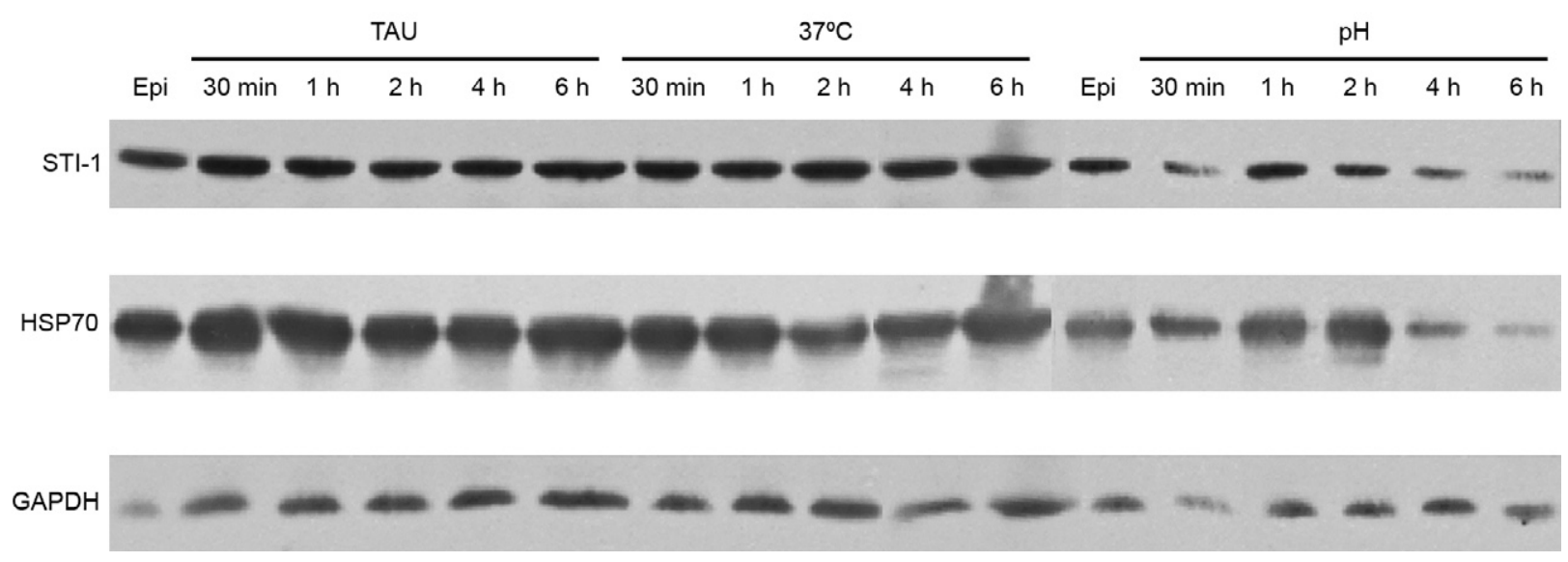

Western blot analysis of Trypanosoma cruzi stressed up to $6 \mathrm{~h}$. Whole-protein extracts ( $20 \mu \mathrm{g})$, obtained from unstressed T. cruzi epimastigotes in the exponential growth phase (Epi) and from epimastigotes subjected to nutritional [triatomine artificial urine (TAU)], heat $\left(37^{\circ} \mathrm{C}\right)$ or $\mathrm{pH}$ stress for $30 \mathrm{~min}$, one, two, for and six hours. Membranes were probed with anti-TcSTI-1 antibody (1:800), anti-HSP70 (1:5000) or anti-GAPDH (1:800) as a control for protein loading. This figure shows one representative result from three independent experiments. 